Methods Children with asthma were recruited. Disease severity was determined by questionnaire and spirometry. Asthma control was assessed by 5-day peak flow variability and children's asthma control test (CACT) on the first and fifth day of peak flow testing. Concentrations of $\mathrm{PM}_{2.5}$ were measured over a 24 -h period in the living room and the child's bedroom.

Results 22 children were recruited, mean age 11.0 years. Across the 22 homes the median time weighted average (TWA) $\mathrm{PM}_{2.5}$ concentration (range) in the living room was $7.4 \mathrm{mg} / \mathrm{m} 3(2.0-150.0)$ and for the bedroom was $5.6(3.1,11.1) \mathrm{mg} / \mathrm{m}^{3}$ ( $\mathrm{p}=0.04$ for comparison with living room). As expected, there was a significantly higher mean TWA $\mathrm{PM}_{2.5}$ in the living rooms and bedrooms of the seven homes where smoking was reported; $22.0 \mathrm{mg} / \mathrm{m}^{3}$ for living rooms in smoking homes and $4.7 \mathrm{mg} / \mathrm{m}^{3}$ for non-smoking homes, $\mathrm{p}=0.001$. There was a positive association between TWA $\mathrm{PM}_{2.5}$ in the living room and peak flow variability ( $r=0.51, p=0.027$, see Abstract P77 Figure 1) and a negative association between TWA $\mathrm{PM}_{2.5}$ in the living room and CACT on day $5(r=-0.48, p=0.037)$. TWA $\mathrm{PM}_{2.5}$ exposure was not related to indices of asthma severity including $\mathrm{FEV}_{1}$ and treatment. Peak $\mathrm{PM}_{2.5}$ concentration was not associated with any outcome.

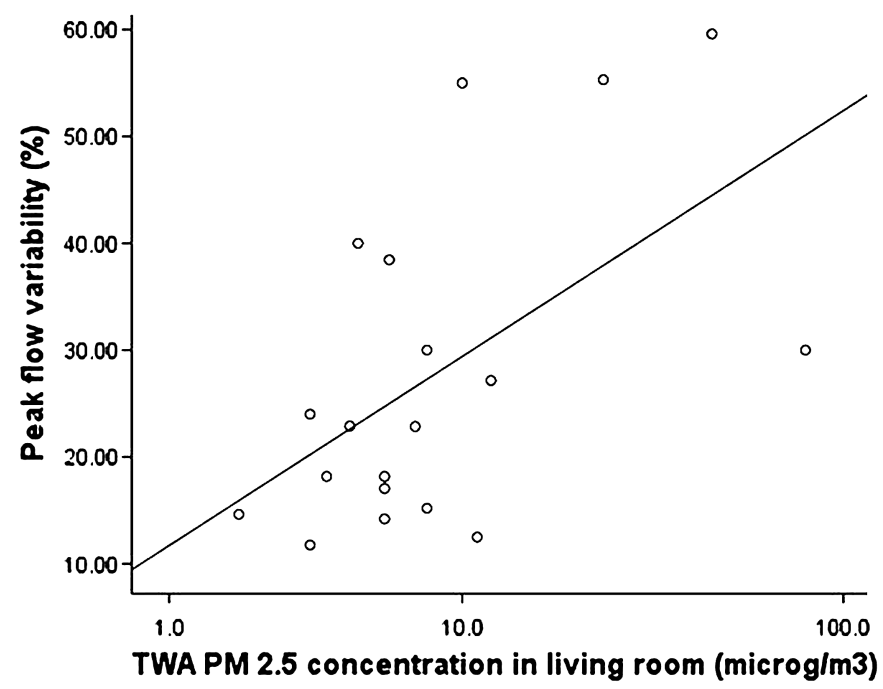

Abstract P77 Figure 1

Conclusions This small study suggests that even at relatively low concentrations, there is an exposure-response relationship between increasing indoor air $\mathrm{PM}_{2.5}$ concentrations, increased airway variability and poorer asthma control in children.

\section{P78 IMPACT OF SEVERE ALLERGIC ASTHMA IN CHILDREN: HIGHLIGHTING A ROLE FOR UNDERSTANDING THE FAMILY PERSPECTIVE}

doi:10.1136/thx.2010.150979.29

${ }^{1} \mathrm{~K}$ G Staley, ${ }^{1} \mathrm{R}$ Herzallah, ${ }^{1} \mathrm{H}$ Pandya, ${ }^{2} \mathrm{E}$ Humphreys, ${ }^{1} \mathrm{E}$ Gaillard. ${ }^{1}$ University of Leicester, Leicester, UK; ${ }^{2}$ Asthma UK, London, UK

Introduction and objectives Current understanding of paediatric severe allergic asthma tends to focus on the impact of the disease on the child in isolation from the impact on the wider family. We aimed to characterise a paediatric severe asthma population and assess the practical, financial and emotional burden on the family.

Methods Case-note review of children (6-18 years) with severe, allergic asthma (BTS treatment step 4-5) was performed; identifying treatments, disease characteristics and practical limitations (e. g. missed schooldays, impingement on activities). Interviews with the primary care-giver of a child with severe allergic asthma were conducted and aimed to explore the impact of severe asthma on the overall family (e.g. missed workdays, time dedicated to care). Family profiles and cost-modelling will be performed to assess the emotional and economic impact on families of having a child with severe allergic asthma.

Results 35 children from a severe asthma clinic between 2007 and 2010 were identified. Despite being on maximum or near-maximum treatment, nearly $50 \%$ of children reported symptoms that impacted on daily activities, or were troublesome at night. Furthermore, $40 \%$ reported poor school attendance due to asthma symptoms. When performed, the Asthma UK Asthma Control Test identified a mean score of 15 (range 10-25); with 5/6 patients reporting a score below 20 (very poor control). Data also suggests that the unpredictable nature of severe asthma has an impact on the child and family unit. For example, it was documented how a child felt 'constantly... frightened of these episodes of shortness of breath'. Parents used the words 'catastrophic' and described how they were simply 'fed-up with poor asthma control', highlighting the perceived impact and frustration at caring for a child with severe asthma. Further work on family profiles and cost-modelling is being undertaken to assess the emotional and economic impact on a family of having a child with severe asthma.

Conclusion These preliminary findings suggest that caring for a child with severe asthma has a considerable impact on the functioning of the family unit. A better understanding of the family perspective on the impact of severe allergic asthma in children may help improve outcomes by enabling the development of specific strategies.

\section{P79 IMPULSE OSCILLOMETRY FOR THE ASSESSMENT OF LUNG FUNCTION DEFICITS ASSOCIATED WITH PRESCHOOL WHEEZING}

doi:10.1136/thx.2010.150979.30

${ }^{1} \mathrm{U}$ Banerjee, ${ }^{1} \mathrm{~S}$ Goldring, ${ }^{2} \mathrm{~J}$ Kirkby, ${ }^{2} \mathrm{~J}$ Stocks, ${ }^{1} \mathrm{~J} 0$ Warner, ${ }^{1} \mathrm{R}$ J Boyle. ${ }^{1} / m p e r i a l$ College London, Department of Paediatrics, London, UK; ${ }^{2}$ UCL, Institute of Child Health, London, UK

Introduction Preschool wheezing affects over $1 / 3$ of children, and is associated with lung function deficits. There is a need for a clinical tool to evaluate lung function in preschool children, which is able to detect pathology associated with wheezing. Spirometry is the most common measurement of lung function in school aged children and adults, however spirometry measurements are a challenge in preschool children when conducted outside of specialised labs due to the complexity of the manoeuvres needed. Impulse oscillometry (IOS) is able to measure the resistance and resonant frequency of the lungs from normal breathing, and may be a suitable tool for assessing lung function in preschool children. This study aimed to measure the success rate of IOS for acquiring high quality lung function data in preschool children, and to evaluate the ability of the technique to detect differences between children with and without a history of wheezing.

Methods We recruited 66 children aged 3-4 years from a hospital paediatric outpatients department. Parents were interviewed about their child's health using a structured questionnaire. Children underwent allergy skin prick testing and lung function assessment using IOS pre- and post-bronchodilator. Variables recorded were resistance across $5-25 \mathrm{~Hz}$, resonant frequency (Fres), reactance at $5 \mathrm{~Hz}$ and the percentage change in resistances across all frequencies post-bronchodilator.

Results 42 (64\%) of 66 children successfully completed lung function assessment using IOS. Younger children were less likely to successfully complete IOS readings (3-3.5 years children $41 \%$ success; $3.5-4$ years children $71 \%$ success; $p=0.03$ ). We found a significant increase in Fres in children with a history of wheezing (mean $23.4 \mathrm{~Hz}$ wheeze, $19.4 \mathrm{~Hz}$ no wheeze; $\mathrm{p}=0.01$ ). Furthermore, 
significant differences were found in the Fres of children who had previously been diagnosed with asthma by a doctor compared to non asthmatics ( $p=0.015)$; and those with atopy and wheeze compared to those with no atopic wheeze $(\mathrm{p}=0.015)$ (Abstract P79 Figure 1).

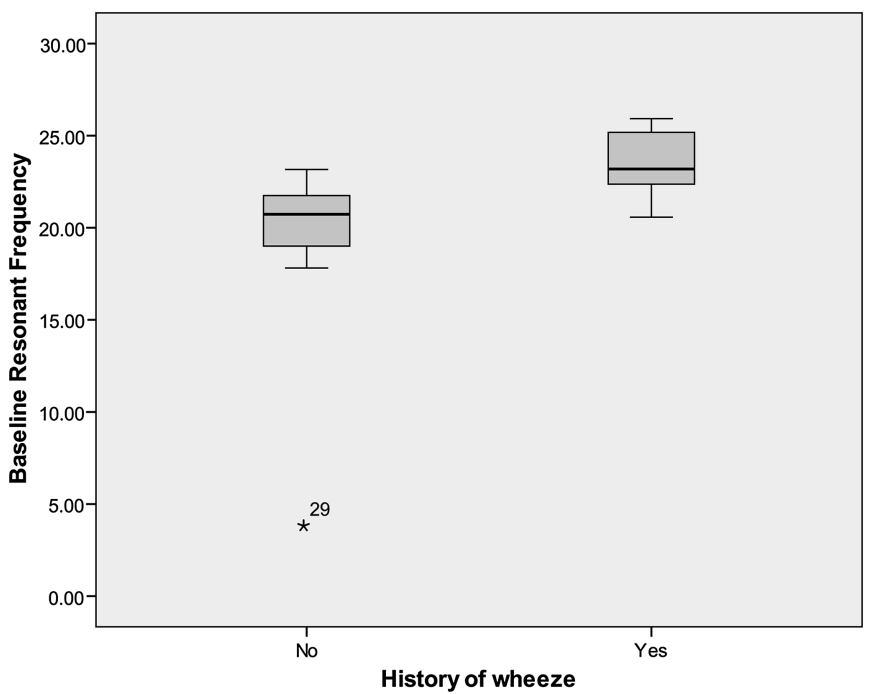

Abstract P79 Figure 1 The differences in resonant frequency between preschool children with a history of wheeze and those without a history of wheeze.

Discussion IOS yields high quality lung function data in most children over 3.5 years age. The technique is able to detect group differences related to wheezing tendency in this age group, and may be a useful clinical tool for use in young children over 3.5 years.

\section{P80 PRE-OPERATIVE ASSESSMENT OF CHILDREN UNDERGOING SCOLIOSIS SURGERY}

doi:10.1136/thx.2010.150979.31

${ }^{1} \mathrm{~A}$ L Ross Russell, ${ }^{2} \mathrm{~S}$ Charlton, ${ }^{3} \mathrm{E}$ R Mooney, ${ }^{3} \mathrm{C}$ Ward, ${ }^{4} \mathrm{R}$ I Ross Russell. ${ }^{1}$ School of Clinical Medicine, John Radcliffe Hospital, Oxford, UK; ${ }^{2}$ Department of Orthopaedics, Addenbrooke's Hospital, Cambridge, UK; ${ }^{3}$ School of Clinical Medicine, Addenbrooke's Hospital, Cambridge, UK; ${ }^{4}$ Department of Paediatrics, Addenbrooke's Hospital, Cambridge, UK

Introduction Historically, assessment of operative risk in children prior to scoliosis surgery has been largely based on pre-operative lung function testing. Children having scoliosis surgery suffer from a wide range of conditions and many are unable to perform lung function testing. Furthermore, the risk of post-operative ventilation is decreasing suggesting better predictors may be needed. We currently evaluate all such patients, using assessment of airway competency, cough strength, and muscle bulk in estimating the risk of requiring post-operative ventilation. Our data suggest that lung function testing is no longer a good predictor of outcome in this group of patients.

Methods We retrospectively reviewed the records of 97 patients who have undergone scoliosis surgery between 2004 and 2010. Pulmonary function testing (PFT) was attempted wherever possible. Patients were clinically assessed prior to surgery, and an estimated risk of post-operative ventilation made. Comparison of each method (PFT and clinical assessment) against a primary outcome of requirement for post-operative ventilation, and secondary outcomes of PICU/HDU and hospital length of stay.

Results PFTwas successful in 68/97 (70\%) of our patients. One child had an FVC $<40 \%$ predicted and three children had FVC $40-50 \%$ predicted. None of these children required ventilation post- operatively. Of the 14 patients who required post-operative ventilation, pulmonary function testing was only possible for four (FVC range $59 \%-74 \%$ predicted). The remaining 10 who needed ventilation were unable to perform PFT. Clinical assessment of risk was highly accurate in predicting the number of children requiring postoperative ventilation in all groups (Abstract P80 Table 1).

\section{Abstract P80 Table 1}

\begin{tabular}{lllll}
\hline $\begin{array}{l}\text { Predicted } \\
\text { risk level }\end{array}$ & No in group & $\begin{array}{l}\text { Predicted } \\
\text { number } \\
\text { ventilated }\end{array}$ & $\begin{array}{l}\text { Actual } \\
\text { number } \\
\text { ventilated }\end{array}$ & $\begin{array}{l}\text { Hospital LoS } \\
\text { (days-median, range) }\end{array}$ \\
\hline Low $(<10 \%)$ & 62 & 3.2 & 3 & $7(4-16)$ \\
Medium (10-30\%) & 20 & 3.1 & 5 & $9(3-21)$ \\
High $(>30 \%)$ & 13 & 6.3 & 5 & $10(3-22)$ \\
\hline
\end{tabular}

Conclusions The group of patients who are most likely to require post-operative ventilation are poor candidates for pulmonary function testing. To assess these children we need to take account of other factors which are important for their respiratory function post-operatively. Clinical assessment of risk can be highly accurate in predicting the need for ventilation following scoliosis surgery.

\section{P81 THE CHANGING INCIDENCE OF PAEDIATRIC EMPYEMA IN NE ENGLAND 2006-2010}

doi:10.1136/thx.2010.150979.32

${ }^{1} \mathrm{M}$ F Thomas, ${ }^{2} \mathrm{C}$ Simmister, ${ }^{1} \mathrm{~S}$ P Rushton, ${ }^{1} \mathrm{D}$ A Spencer. ${ }^{1}$ Newcastle University, Newcastle-Upon-Tyne, UK; ${ }^{2}$ Newcastle-upon-Tyne NHS Foundation Trust, Newcastleupon-Tyne, UK

Introduction and objectives The incidence of empyema has been increasing in children. We investigated trends in the incidence of empyema cases over the time period 2006-2010 in relation to temperature, rainfall and the introduction of the pneumococcal vaccine using regression analysis.

Methods All admissions with ICD-10 codes J86.0 and J86.9 coding for pyothorax with/without fistula from 1st January 2006 until 31st May 2010 were collated. A generalised least squares (GLS) modelling technique was employed to investigate trends in child cases in relation to local average monthly maximum temperature and monthly rainfall. The timing of the introduction of the PCV-7 vaccine was included as a co-variate.

Results 183 cases of paediatric empyema were identified. There was a negative relationship between number of cases of childhood empyema and average maximum temperature in the month of admission ( $t=-2.24, p>0.00)$. Introduction of the PCV-7 vaccine was associated with a reduction in cases $(t=-5.00, p=0.02)$. There was no significant relationship between the number of cases and average monthly rainfall. There was no significant evidence of autocorrelation for this model suggesting that the number of cases each month were independent of the number in the preceding or following month. Fitted values from the model and the observed trend in cases are shown in Abstract P81 Figure 1. The number of cases appears to be inversely related to temperature variation across the year. The R-squared of the final model was 0.36, whilst the $\mathrm{R}$-squared for model without the vaccine was 0.30 , suggesting that $6 \%$ of the variation in cases could be explained by the introduction of the vaccine.

Conclusions Mean maximum temperature in the month of admission appears to be a significant predictor of cases of empyema and correlates with the cyclical pattern of cases. Introduction of PCV-7 vaccine was associated with a reduction in the number of cases which may be related to a combination of direct and indirect vaccine effects secondary to improved herd immunity. Further work is 